\title{
Foro de solidaridad
}

\author{
Solidarity forum
}

\begin{abstract}
Nuestro compañero y amigo Gastão Wagner de Sousa Campos, sanitarista de gran trayectoria en el Movimiento de Reforma Sanitaria brasileño, ex Secretario de Salud del Municipio de Campinas, ideólogo y responsable del fortalecimiento del Sistema Único de Salud (SUS) de Brasil, está siendo injustamente acusado, por una causa iniciada con posterioridad a su renuncia al cargo de Secretario Ejecutivo del Ministerio de Salud de Brasil.

Uniéndonos a las organizaciones que han hecho público su repudio, recopilamos aquí las opiniones vertidas por el representante de la Associação Brasileira de Pós-Graduação em Saúde Coletiva (ABRASCO), como así también el texto de Marcelo Manzano Un "forum privilegiado" para Gastão, el cual relata el clima vivido en el acto de desagravio convocado por distintas agrupaciones y personalidades encabezadas por Nelson Rodrigues dos Santos -presidente del Instituto de Direito Sanitário Aplicado (IDISA)- en defensa de la idoneidad ético-política de Gastão.
\end{abstract}

\section{DECLARACIÓN DE ABRASCO}

Gastão es un ilustre compañero del Movimiento Sanitario, que ha jugado un papel destacado en la construcción del Sistema Único de Salud (SUS), universal, integral, descentralizado y, sobre todo, participativo.

La agresión a nuestro compañero de lucha por la democracia en el ámbito de la salud y por una sociedad inclusiva, no puede pasar sin un grito de solidaridad.

Esta agresión no alcanza exclusivamente al compañero Gastão Wagner. Es una ofensa a todo el movimiento sanitario brasileño.

Elegimos al agredido como legítimo representante de un segmento de la sociedad que se ha destacado, nacional e internacionalmente, por el desapego a los bienes y regalías materiales, que ha contribuido a la construcción de un mundo mejor para todos en el área de la salud.
Somos herederos de los sanitaristas que, por lo menos desde el inicio del siglo pasado se esmeraron por aportar las mejores condiciones para el avance en este campo. Para destacar solo un hecho: fueron los sanitaristas brasileños, asociados con los sanitaristas chinos, los que propusieron en 1945 en San Francisco, la creación de la Organización Mundial de la Salud (OMS).

Lo que está en juego no es solo su intachable competencia, necesitamos reaccionar contra la alevosía y rescatar la dignidad herida de todo el movimiento sanitario brasileño.

Por lo tanto, nuestra solidaridad no es solo con el compañero herido, es un gesto altivo de protesta contra la agresión que todos sufrimos.

José da Rocha Carvalheiro

Presidente de la Associação Brasileira de Pós-Graduação em Saúde Coletiva (ABRASCO)

\section{UN "FORUM PRIVILEGIADO" PARA GASTÃO}

Hoy, 3 de junio, durante el período del almuerzo, se vivió un bellísimo acto de solidaridad para con el sanitarista y hombre público, Gastão Wagner de Sousa Campos.

Reunidos en el honorable salón de la Facultad de Ciencias Médicas de la Universidad de Campinas (Unicamp), nombres ilustres del movimiento sanitario, jóvenes militantes de la salud pública, trabajadores del sector público comprometidos con la construcción del Sistema Único de Salud (SUS), profesores, alumnos, amigos, representantes de diferentes consejos de la sociedad civil, órganos de clase, en fin, una legítima y democrática arena pública, se manifestó enfática y unánimemente contra los infames y absurdos procesos criminales y civiles que acusan al profesor Gastão de estar involucrado con la denominada "Operación Sanguijuela". 
Cuando fue Secretario Ejecutivo del Ministerio de Salud de Brasil, autorizó proyectos de diputados que proponían la transferencia de recursos a entidades (Santas Casas, hospitales, municipios, que componen el SUS) para que éstas adquirieran ambulancias. Ocurre que los propios diputados autores de los proyectos -mancomunados con las empresas de equipamiento de ambulancias- hacían llegar los documentos (preproyectos) a las entidades, induciéndolas a contratar los servicios de las empresas del esquema, que obviamente realizaban los servicios a precios sobrefacturados.

Pues bien, aunque Gastão, como representante legal del Ministerio, haya autorizado los proyectos, él ya no estaba en el cargo cuando efectivamente ocurrieron los procesos de transferencia de recursos hacia las entidades (entiéndase: entidades hasta entonces consideradas idóneas y prestadoras regulares del SUS), ni cuando fueron realizadas las contrataciones y las ejecuciones de los servicios de equipamiento de ambulancias, ni tampoco cuando éstos fueron pagados. O sea, todo lo ilícito se produjo en un período posterior a su gestión, cuando él ya había dejado el Ministerio, justamente por estar en desacuerdo con los métodos del entonces ministro Humberto Costa.

Sin embargo, por el ensañamiento justiciero del poder judicial brasileño, Gastão está siendo considerado como miembro del esquema, como si estuviera articulado con los diputados y las empresas de equipamiento de ambulancias desde su origen; es decir, desde la autorización del proyecto. Se olvidaron, por ejemplo, que él nunca tuvo ninguna vinculación previa con los diputados, ni mucho menos con las empresas; que él jamás fue beneficiario de los recursos apropiados por los tales "Sanguijuelas"; que él además vive una vida de asalariado; que él Ilamó a la Policía Federal y a la Contraloría General de la Unión (CGU) para investigar esquemas de corrupción dentro del Ministerio (lo que resultó en la llamada "Operación Vampiro").

De ser condenado en los diversos procesos, además de multas que superan la cifra de un millón de reales, será encarcelado por hasta 12 años, perderá sus derechos políticos y jamás podrá actuar en el sector público, donde siempre estuvo, sea como profesor o como gestor del SUS.
Por todo esto, por la aterradora narrativa kafkiana contrapuesta a su historia de vida, por el significado del movimiento sanitario como vanguardia de las políticas sociales ante una justicia que se escuda en la retaguardia reaccionaria de las instituciones políticas, el acto de hoy fue más que una manifestación de desagravio, como anunciaba la invitación; más que un acto de protesta, como imaginábamos los indignados. Se transformó en un gran momento cívico, de defensa de la salud pública, de los derechos humanos, de las políticas universales, de la radicalización de la democracia, de expresión de la Política.

$Y$ fueron muchos los relatos que aportaron emoción al auditorio colmado. Entre lecturas de apoyo de autoridades públicas de todos los rincones del país, los presentes recordaban que el proceso contra Gastão no lo alcanza solo a él como persona física, sino también a todos nosotros que luchamos dentro de la esfera pública, contra un océano de adversidades, con la esperanza de producir una sociedad más digna, más saludable, más justa, más alegre. Otros recordaban que, para aquellos que trabajaron o estudiaron con él, su nombre remite a la idea de inventor del futuro. De hecho, Gastão es de esos sujetos que dan el paso sin tener certeza de la firmeza del puente; sino que, por compromiso absoluto con la acción política, va al frente. Algunos de los que estuvieron junto a él en la lucha, en el cotidiano de los Centros de Salud, recordaban cuán fundamental fue su batalla intransigente para que los profesionales de la salud aprendieran a escuchar y acoger a las personas.

Claro, muchos hablaron sobre su trayectoria en el movimiento sanitario, en la construcción del SUS, y todos hablaron de su incuestionable conducta ética.

Por último, Thiago, un ex alumno, concluyó de forma brillante. Describió aquel acto como un verdadero y legítimo "forum privilegiado" en el que, de hecho, Gastão fue juzgado y absuelto.

Marcelo Manzano

Economista. Asesor técnico de la Secretaría de Asistencia Social del Municipio de Campinas, Brasil. marmanzo@gmail.com 